\title{
Effects of estrogen receptor and estrogen on the chromatin structure in estrogen receptor stable transfectants
}

\author{
Young Joo Lee ${ }^{1,3}$, Won Chung Lim ${ }^{1}$, Ying Hua \\ $\mathrm{Jin}^{2}$, and Seung Ki Lee ${ }^{2}$ \\ ${ }^{1}$ Institute of Bioscience, Department of Bioscience and Biotechnol- \\ ogy, College of Engineering, Sejong University, Seoul, Korea \\ ${ }^{2}$ College of Pharmacy, Seoul National University, Seoul, Korea \\ ${ }^{3}$ Corresponding author: Tel, +82-2-3408-3766, \\ Fax, +82-2-3408-3569; E-mail, yjlee@ sejong.ac.kr
}

Accepted 2 April 2002

Abbreviations: ER, estrogen receptor; ERE, estrogen response elements; PR, progesterone receptor.

\begin{abstract}
The estrogen receptor (ER), a member of the nuclear hormone receptor superfamily recruits coactivators that modify local chromatin structure. Here we investigated the effect of the estrogen receptor and estrogen on the global chromatin structure and the local chromatin structure of the progesterone receptor gene during the process of transcriptional activation using Rat1+ER cells stably expressing the estrogen receptor. The total chromatin was more accessible to DNasel in Rat1+ER cells than in the parental estrogen receptor-negative Rat 1 cells. After $18 \mathrm{~h}$ of estrogen treatment, total chromatin was more dispersed in Rat1+ER cells than in Rat1 cells. The chromatin structure of the progesterone receptor gene was more sensitive to DNasel in Rat1+ER cells than in Rat1 cells. However, the chromatin structure of the progesterone receptor gene did not change further on estrogen treatment. Our results suggest that under certain circumstances unoccupied estrogen receptors may play some role in reorganizing the repressive chromatin structure to induce gene activation.
\end{abstract}

Key Words: Estrogen, Estrogen receptor, Progesterone receptor, DNasel sensitivity, Chromatin

\section{Introduction}

An estrogen-occupied estrogen receptor (ER) bound to estrogen response elements (ERE) can activate or repress transcription (Beato and Klug, 2000). The disruption of chromatin structure has been implicated in estrogen-induced transcription activation (Burch and Weintraub, 1983; Burch and Fischer, 1990; DiRenzo et al., 2000; Pham et al., 1991; Seyfred and Gorski, 1990). Unoccupied ERs are associated with the chromatin as determined by in vivo crosslinking experiments (Wrenn and Katzenellenbogen, 1990). However, it is still unclear whether there is a direct relationship between estrogeninduced transcription and changes in chromatin structure (Mao and Shapiro, 2000). Transcription activation parallels chromatin structural changes in the promoter region of minichromosomes containing the $5^{\prime}$ flanking region of the prolactin gene in rat pituitaryderived $\mathrm{GH}_{3}$ cells (Seyfred et al., 1989). SWI-SNF proteins, which facilitate transcription by remodeling chromatin (Peterson and Tamkun, 1995), are required for estrogen-induced transcription in yeast (Yoshinaga et al., 1992). However, there are evidences to suggest that no direct correlation exists between transcription and chromatin structural remodeling: DNasel hypersensitive sites of the prolactin gene appear early in development and do not change further with estrogen treatment (Durrin and Gorski, 1985); and transcription activation of the vitellogenin gene is poorly correlated with chromatin changes (Burch and Evans, 1986).

In this study, we addressed these issues by examining changes in chromatin structures and their sensitivity toward DNasl in the stably transfected cells with ER (Rat1+ER). Rat1 cells that do not express endogenous ER were transfected with retroviral-vector construct containing human ER cDNA and stably ER expressing cells referred as Rat1+ER (Kaneko et al., 1993). Rat1+ER cells expressed physiological levels of ER per cell, and activated the silent endogenous progesterone receptor (PR) gene on estrogen treatment (Kaneko et al., 1993). The PR gene transcription rate gradually increased during a $24 \mathrm{~h}$ of estrogen treatment after an initial lag of 1-3 h (Lee and Gorski, 1996). It was suggested that the unoccupied ER may likely be bound to the chromatin and changes in chromatin structure was taken place for the gradual estrogen-induced PR gene transcription. To test this hypothesis, we examined DNasel sensitivity of total chromatin and the chromatin of the $5^{\prime}$ flanking regions and exon 1 of the PR gene. The presence of the unoccupied ER alone modified the chromatin structure of the PR gene as well as the total chromatin of Rat $1+E R$ cells. Estrogen treatment of Rat1+ER cells caused an increase in DNasel sensitivity at $18 \mathrm{~h}$ of the estrogen treatment; however, no changes in the chromatin of the PR gene were detected. The estrogen-induced gradual increase in the rate of 
transcription of the PR gene was not due to the chromatin changes in the $5^{\prime}$ flanking regions and exon 1 of the gene. These results suggest that the unoccupied ER is already bound to the chromatin, which leads to a structural change under some circumstances, such as in our clonal cell line.

\section{Materials and Methods}

\section{Cell Culture}

Rat1 and Rat1+ER cells were grown in phenol red-free Dulbecco's modified Eagles medium (DMEM; Sigma, USA) supplemented with $10 \%$ fetal bovine serum (FBS; Hyclone, USA). Cells were grown at $37^{\circ} \mathrm{C}$ in humidified $95 \%$ air $/ 5 \% \quad \mathrm{CO}_{2}$ and fed every $1-2$ day. Before trreatment with 17- $\beta$-estradiol (Sigma), the cells were incubated for 24-48 $\mathrm{h}$ in DMEM, supplemented with $10 \%$ dextran-charcoal stripped FBS (ST-FBS). All estrogen treatments were done with medium containing ST-FBS. To maximize the response, $10 \mathrm{nM}$ of estrogen was used.

\section{Chromatin Analysis}

Cells were harvested by trypsinization, washed, and lysed in $0.25 \%$ Nonidet P-40 buffer $[10 \mathrm{mM}$ Tris- $\mathrm{HCl}, 3$ $\mathrm{mM} \mathrm{CaCl}, 2 \mathrm{mM} \mathrm{MgCl}, 1 \mathrm{mM}$ dithiothreitol (DTT), and $10 \%$ glycerol]. Nuclei were suspended immediately in DNasel digestion buffer $(20 \mathrm{mM}$ Tris- $\mathrm{HCl}, \mathrm{pH} 7.5,60$ $\mathrm{mM} \mathrm{KCl}, 15 \mathrm{mM} \mathrm{NaCl}, 0.5 \mathrm{mM}$ DTT, $5 \mathrm{mM} \mathrm{MgCl}_{2}, 1 \mathrm{mM}$ $\mathrm{CaCl}_{2}$, and $10 \%$ glycerol). Increasing amounts of DNasel were added and incubated at room temperature for $20 \mathrm{~min}$, except that nuclei from $\mathrm{GH}_{3}$ cells were treated for $6 \mathrm{~min}$. Reaction was stopped by adding sodium dodecyl sulfate (SDS)-RNaseA-EDTA solution. Genomic DNA was isolated by proteinase $\mathrm{K}$ digestion overnight at $55^{\circ} \mathrm{C}$, phenol/chloroform extraction, and ethanol precipitation (Shin et al., 2000; Sun and John, 2000). Aliquots of isolated genomic DNA were visualized by agarose gel electrophoresis to examine global chromatin structural change. The rat PR sequences and clones (Kraus et al., 1994) were a gift from Dr. Kelly E. Mayo at Northwestern University. The map of the $5^{\prime}$ flanking regions of the PR gene examined is illustrated in Fig. 3. EcoRI was used to cleave the PR gene. EcoRI digestion of the genomic DNA results in a 3.1-kilobase $(\mathrm{kb})$ parental PR fragment, which is from nucleotides -1378 to +1759 . This $3.1-\mathrm{kb}$ fragment includes both the distal and proximal promoters and two of the five EREs identified by Katzenellenbogen's group at $-11059 /-11037$ and $+615 /+637$, respectively (Kraus et al., 1994). A DNasel cut within the area, i.e., a DNasel hypersensitive site, results in a sub-fragment. The length of the sub-band is the distance between the EcoRI cut and the DNasel hypersensitive site. The PR probe that was used in this assay is a $987 \mathrm{bp} \mathrm{Pstl}$ fragment, from +637 to +1624 . Thirty micrograms of DNasel-treated genomic DNA were digested with EcoRI and fractionated by electrophoresis in a $1 \%$ agarose gel in 1x TAE buffer (40 mM Tris-acetate, $1 \mathrm{mM}$ EDTA). After electrophoresis, the DNA within the gel was depurinated $(0.25 \mathrm{~N} \mathrm{HCl})$ for $10 \mathrm{~min}$, denatured $(1.5 \mathrm{M}$ $\mathrm{NaCl}, 0.5 \mathrm{~N} \mathrm{NaOH})$ for 30 min, neutralized $(0.5 \mathrm{M}$ Tris$\mathrm{HCl} \mathrm{pH} \mathrm{7.0,1.5} \mathrm{M} \mathrm{NaCl)} \mathrm{for} 30 \mathrm{~min}$, treated in 20x SSC ( $3 \mathrm{M} \mathrm{NaCl}, 0.3 \mathrm{M}$ sodium citrate, $\mathrm{pH}$ 7.0) for $30 \mathrm{~min}$, and transferred downward to a nylon membrane (Schleicher \& Schuell). The hybridization was done in 5x SSPE ( $0.75 \mathrm{M} \mathrm{NaCl}, 50 \mathrm{mM} \mathrm{NaH}_{2} \mathrm{PO}_{4}$, and $5 \mathrm{mM}$ EDTA), $5 \mathrm{x}$ Denhardt's solution (15\% Ficoll, 0.1\% polyvinylpyrrolidone, and $0.1 \%$ bovine serum albumin), $0.5 \%$ SDS, and $100 \mu \mathrm{g} /$ $\mathrm{ml}$ of denatured and sheared herring sperm DNA at $65^{\circ} \mathrm{C}$ for $36-48 \mathrm{~h}$. Probes were labeled with ${ }^{32} \mathrm{P}-\alpha-\mathrm{dATP}$ by a random priming method. The membranes were washed with $0.2 x$ SSC $(0.3 \mathrm{M} \mathrm{NaCl}, 0.03 \mathrm{M}$ sodium citrate, $\mathrm{pH} 7.0) / 0.1 \%$ SDS at $65^{\circ} \mathrm{C}$ for $1 \mathrm{~h}$, exposed, and visualized by either Phosphorimager (Molecular Dynamics) or autoradiography.

\section{Results}

\section{Effects of unoccupied ER on the global chromatin structure}

The chromatin organization of the Rat1 and Rat1+ER cells was compared. Nuclei from each cell type were isolated and treated with increasing amounts of DNasel simultaneously. Genomic DNA isolated from DNaseltreated nuclei was examined for the susceptibility of the total chromatin toward DNasel by comparing the rates of

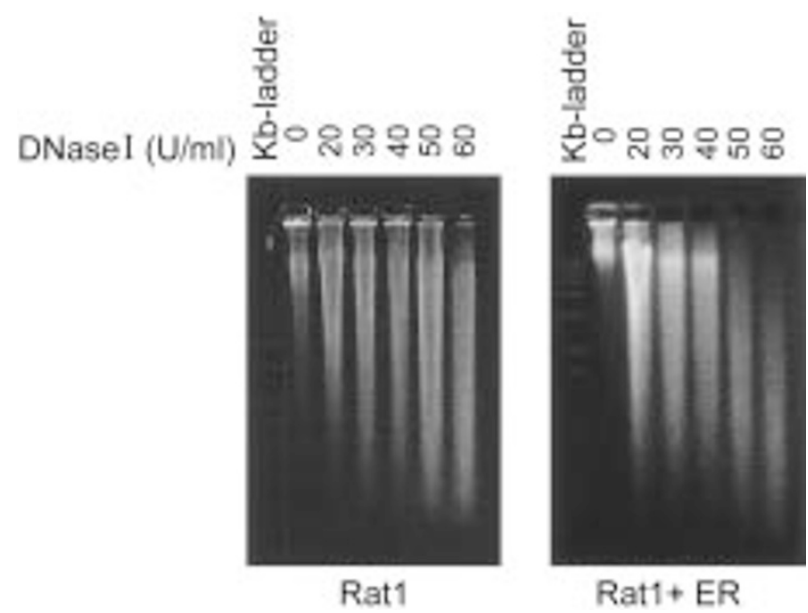

Figure 1. Chromatin structure in Rat1 and Rat1+ER Cells. Nuclei from Rat1 and Rat1+ER cells were simultaneously treated with increasing concentrations of DNasel as indicated. Genomic DNA was purified and visualized by agarose gel electrophoresis. A 1-kb ladder was used as a size marker. The samples from Rat 1 cells and Rat $1+E R$ cells are indicated on the figure. 


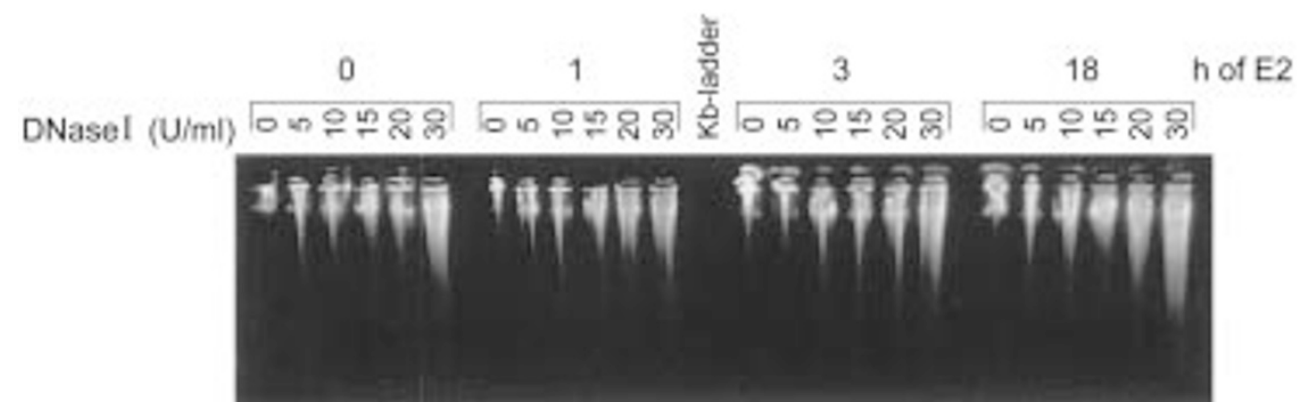

Figure 2. Time-course of chromatin changes in Rat1+ER Cells. Rat1+ER cells were treated with estrogen for the indicated times and harvested simultaneously. Nuclei were isolated and treated with increasing concentrations of DNasel as indicated. A 1-kb ladder was used as a size marker. The estrogen treatment periods are indicated at the top of the figure.

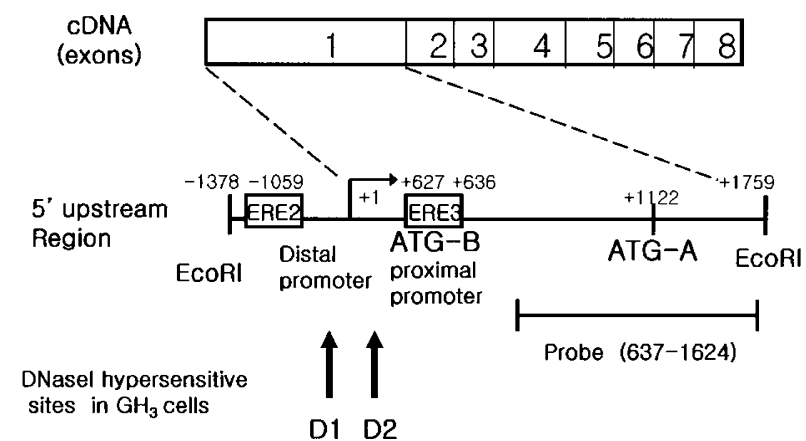

Figure 3. Schematic representation of the cDNA, the $5^{\prime}$ flanking regions, and the locations of DNasel hypersensitive sites of the rat PR gene. Positions of the exons (numbered 1-8) and map of the $5^{\prime}$ flanking regions and exon 1 of the rat PR gene are shown. Positions of the EcoRI sites and the $987 \mathrm{bp}$ Pstl PR probe used in the DNasel hypersensitive sites mapping are indicated. The $3.1-\mathrm{kb} E c 0 \mathrm{Rl}$ fragment includes both the distal and proximal PR promoters, two translation start sites (ATG-B at +627 ; ATG-A at +1122 ) for PR $A$ and $B$ isoforms, and two EREs. Map is not drawn to scale. The positions of the two DNasel hypersensitive sites are designated as D1 and D2. D1 is adjacent to the distal promoter and D2 is in the vicinity of the proximal promoter, which overlaps the translational start site of the $\mathrm{PR} B$ isoform and the internal ERE.

genomic DNA degradation (Figure 1). The chromatin of the Rat $1+E R$ cells required less DNasel to be degraded than did the chromatin of the Rat1 cells, suggesting that the chromatin was more dispersed by the presence of ER.

\section{Effects of estrogen on the global chromatin structure}

The time-course of the estrogen-induced chromatin change in Rat1+ER cells was examined (Figure 2). Equal numbers of cells were seeded, treated with estrogen at different times, and harvested at the same time. Nuclei were treated with increasing concentrations of DNasel and genomic DNA was purified. There was no significant global chromatin structure difference between 0,1 , and $3 \mathrm{~h}$ of estrogen treatment, respectively. However, the chromatin was more susceptible to DNasel at $18 \mathrm{~h}$ of estrogen treatment, suggesting that estrogen slowly

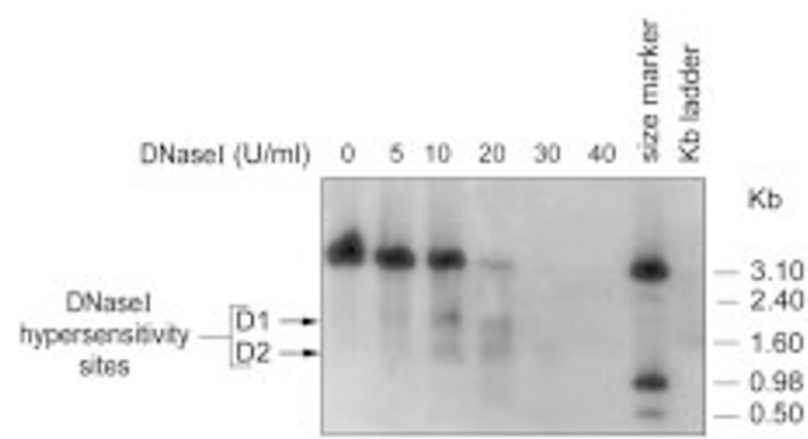

Figure 4. Chromatin Structure of the PR Gene in $\mathrm{GH}_{3}$ Cells. Nuclei from $\mathrm{GH}_{3}$ cells were treated with increasing concentrations of DNasel. Genomic DNA was digested with EcoRI. The $3.1-\mathrm{kb}$ parental EcoRI bands are indicated. A size marker was prepared by cutting the PR plasmids with several restriction enzymes and loading approximately $10 \mathrm{pg}$ aliquots to clearly designate the location of the DNasel hypersensitive sites. The positions of the DNasel hypersensitive sites are designated D1 and D2, as shown in Fig. 3.

has been observed in several experiments and at other time points up to $36 \mathrm{~h}$.

\section{Chromatin structure of the endogenous PR gene in $\mathrm{GH}_{3}$ cells}

Next, we examined specific chromatin structure changes of $5^{\prime}$ flanking and exon 1 of the endogenous PR gene. Initially, DNasel hypersensitive sites of the PR gene were mapped in $\mathrm{GH}_{3}$ cells (Figure 3), where the PR gene is actively expressed. DNasel hypersensitive sites are associated with important regulatory regions and are good criteria for determining chromatin structure disruption at specific local sites. Purified genomic DNA from DNaseltreated nuclei was digested with EcoRl and probed by an indirect end-labeling. Two DNasel hypersensitive sites were clearly detected (Figure 4). One is located near the distal promoter region and the other is at the proximal promoter, which overlaps one ERE. These locations are labeled D1 and D2 in Figure 3, respectively. 


\section{Effects of unoccupied ER on the chromatin structure of the PR gene}

The chromatin structures of the $5^{\prime}$ flanking and exon 1 of the PR gene in Rat1 and Rat1+ER cells were compared. Nuclei from either cell type were isolated and treated with DNasel simultaneously. Genomic DNA was purified from each sample, digested with EcoRl, and probed as shown in Figure 3. DNasel degraded the PR gene in Rat1+ER cells faster than it degraded the gene in Rat1 cells (Figure 5). However, there was no DNasel hypersensitive site on the PR gene in Rat1 or Rat1+ER cells. This indicated that the chromatin structures of the $5^{\prime}$ flanking regions and exon 1 of the PR gene in Rat1+ER cells were more exposed than in Rat1 cells, although there were no specific changes in the local regions.

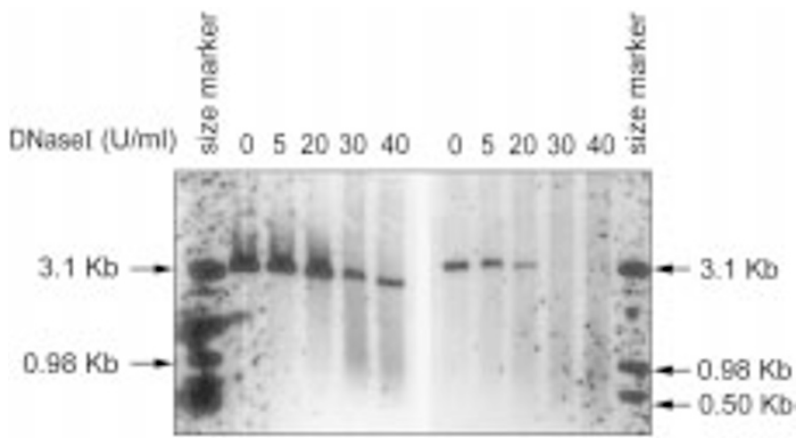

Figure 5. Chromatin structure of the PR gene in Rat1 and Rat1+ER cells. Nuclei from Rat1 and Rat1+ER cells were treated with increasing concentrations of DNasel. Genomic DNA was purified and digested with EcoRI. The 3.1-kb parental EcoRI bands are indicated. The lane containing the size marker is labeled.

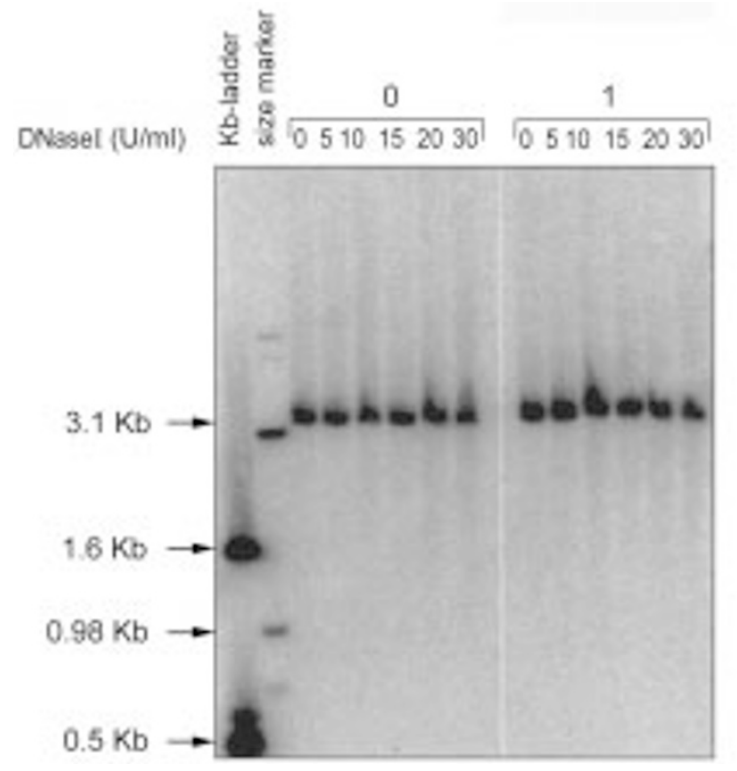

\section{Effects of estrogen on the chromatin structure of the PR gene}

We hypothesized that the gradual increase in the rate transcription of the PR gene (Lee and Gorski, 1996) accompanies the disruption of the chromatin structure of the PR gene. The effect of estrogen treatment on the chromatin structure of the PR gene with time in Rat1+ER cells was examined (Figure 6). No DNasel hypersensitive sites were detected and the DNasel sensitivity of the PR gene did not change with estrogen treatment.

\section{Discussion}

We examined the effects of unoccupied ER on chromatin structure by comparing the structures in parental ER-negative Rat1 and Rat1+ER cells. The global chromatin structure and the chromatin structure of the $5^{\prime}$ flanking regions and exon 1 of the PR gene of the Rat1+ER cells were significantly dispersed as compared with the Rat1 cells. It appears that the presence of the ER itself caused this effect.

Interestingly, estrogen slowly caused the entire chromatin of Rat1+ER cells to be more dispersed. Vic et al. (1980) reported that estrogen induced decondensation of the entire chromatin in rat endometrium within $1 \mathrm{~h}$. This effect appears to be related to transcription activity, because it is sensitive to actinomycin $D$ but not to cycloheximide (Vic et al., 1980). However, it is not known how these effects influence the transcription of specific estrogen-responsive genes.

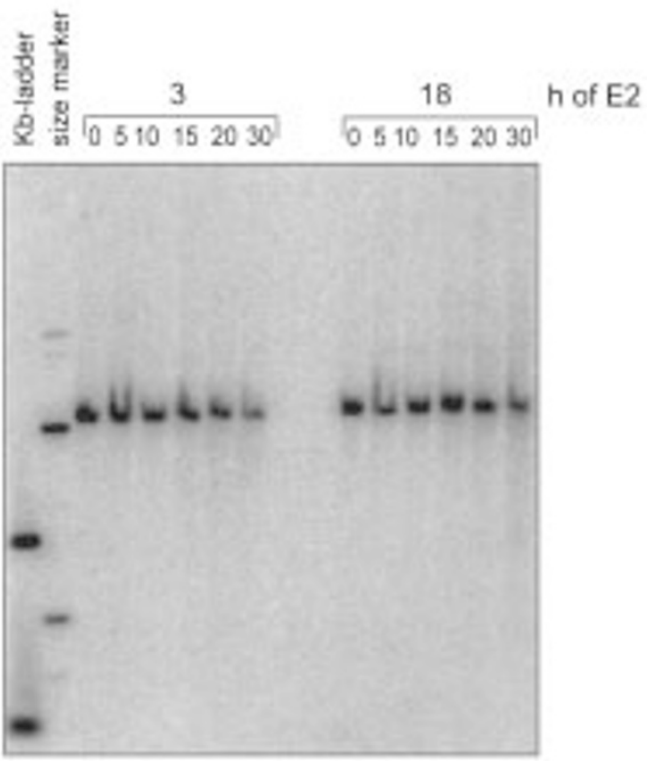

Figure 6. Time-course of chromatin change of the PR gene in Rat1+ER cells. Rat1+ER cells were treated with estrogen for the indicated times. The DNasel concentration for each lane is shown at the top. The $3.1-\mathrm{kb}$ parental $E c \mathrm{RI}$ bands are indicated. The lanes containing a $1-\mathrm{kb}$ ladder and size marker are labeled. 
We examined whether the chromatin structure of the PR gene remodeled with activation of transcription. However, the DNasel hypersensitive sites in the $5^{\prime}$ flanking regions and exon 1 of the PR gene present in $\mathrm{GH}_{3}$ cells were not detected with transcription activation in Rat1+ER cells. It appears that mechanisms other than changes in chromatin structure enhance PR gene transcription in Rat1+ER cells, although it is possible that the EREs located outside the region examined are being regulated. There is evidence that chromatin structure does not always correlate with transcription. A truncated ER devoid of transcription activation function induces chromatin changes, indicating that some chromatin changes are due solely to DNA binding (Gilbert et al., 1992). The administration of exogenous estrogen activates the silent vitellogenin gene (Burch and Weintraub, 1983). This is accompanied by an initial lag; however, subsequent induction of the gene by estrogen is much more efficient with no such a lag, indicating that the initial exposure to estrogen introduces modifications in the genome that facilitate transcription (Burch and Evans, 1986). This "memory effect" induced by estrogen is not due to chromatin structure changes or methylation states of the gene (Burch and Evans, 1986).

We did not find direct correlation between estrogeninduced transcription of the PR gene and DNasel sensitivity changes of the $5^{\prime}$ flanking regions and exon 1 of the PR gene. This was probably due to the detection limit of the methodology that we used. However, our results suggest that the unoccupied ER may already bound to the chromatin and may play a role in reorganizing chromatin that represses transcription activation in some circumstances, such as in our clonal cell line.

\section{Acknowledgements}

This work was supported in part by grants from the Korean Ministry of Health and Welfare (HMP-00-O21600-0009; YJL), and the Korean Science and Engineering Foundation (2000-1-20700-005-3; SKL).

\section{References}

Beato M, Klug J. Steroid hormone receptor: An update. Hum Reprod Update 2000;6:225-36

Burch JB, Evans MI. Chromatin structural transition and the phenomenon of vitellogenin gene memory in chickens. Mol Cell Biol 1986;6:1886-93

Burch JB, Fischer AH. Chromatin studies reveal that an ERE is located far upstream of a vitellogenin gene and that a distal tissue specific hypersensitive site is conserved for two coordinately regulated vitellogenin genes. Nucleic Acids Res 1990;18:4157-65

Burch JB, Weintraub $\mathrm{H}$. Temporal order of chromatin structural changes associated with activation of the major chicken vitellogenin gene. Cell 1983;33:65-76

DiRenzo J, Shang Y, Phelan M., Sif S., Myers M., Kingston R and Brown M. BRG-1 is recruited to estrogen-responsive promoters and cooperates with factors involved in histone acetylation. Mol Cell Biol 2000; 20:7541-49

Durrin LK, Gorski J. The prolactin gene hypersensitive site are present early in development and not induced by estrogen administration. Endocrinology 1985;117:2098-05

Gilbert DM, Losson R, Chambon P. Ligand dependence of estrogen receptor induced change in chromatin structure. Nucleic Acids Res 1992;20:4525-31

Kaneko KJ , Gelina C, Gorski J. Activation of the silent progesterone receptor gene by ectopic expression of estrogen receptors in a rat fibroblast cell line. Biochemistry 1993;32: 8348-59

Kraus WL, Montano MM, Katzenellenbogen BS. Identification of multiple, widely spaced estrogen-responsive regions in the rat progesterone receptor gene. Mol Endocrinol 1994;8:952-69

Lee YJ, Gorski J. Estrogen-induced transcription of the progesterone receptor gene does not parallel estrogen receptor occupancy. Proc Natl Acad Sci USA 1996;93:15180-84

Mao C, Shapiro DJ. A histone deacetylase inhibitor potentiates estrogen receptor activation of a stably integrated vitellogenin promotor in HepG2 cells. Endocrinology 2000; 141:2361-69

Peterson CL, Tamkun JW. The SWI-SNF complex: a chromatin remodeling machine? Trends Biochem Sci 1995; 20:143-46

Pham TA., Hwung YP, McDonnell DP, OMalley BW. Transactivation functions facilitate the distruption of chromatin structure by estrogen receptor derivatives in vitro. J Biol Chem 1991;266:18178-87

Seyfred MA, Gorski J. An interaction between the 5 flnking distal and proximal regulatory domains of the rat prolactin gene is required for transcription activation by estrogen. Mol Endocrinol 1990;4:1226-34

Seyfred MA., Kladde MP, Gorski J. Transcriptional regulation by estrogen of episomal prolactin gene regulatory element. Mol Endocrinol 1989;3:305-14

Sun HC, John HW. Characterization of an unusual variant mRNA of human lysosomal á-mannosidase. Exp. Mol. Med. 2000;32:187-92

Shin JY, Kim HS, Lee KS, Kim JB, Park JB, Won MH, Chae SW, Choi YH, Choi KC, Park YE, Lee JY. Mutation and expression of the $\mathrm{p} 27^{\mathrm{kip} 1}$ and $\mathrm{p} 57^{\mathrm{kp} 2}$ genes in human gaastric cancer. Exp. Mol. Med. 2000;32:79-83

Vic P, Garcia M, Humeau C, Rochefort H. Early effect of estrogen on chromatin ultrastructure in endometrial nuclei. Mol Cell Endocrinol 1980;19:79-92

Wrenn CK, Katzenellenbogen BS. Cross-linking of estrogen receptor to chromatin in intact MCF-7 human breast cancer cell: optimization and effect of ligand. Mol Endocrinol 1990;4: 1647-54

Yoshinaga SK, Peterson CL, Yamamoto KR. Roles of SWI1, SWI2 and SWI3 proteins for transcriptional enhancement by steroid receptors. Science 1992;258:1598-604 